\title{
Epidemiology and pathology of onchocercosis of cattle in Bangladesh
}

\author{
M Asaduzzaman, MAA Mamun, Anisuzzaman*, MA Alim, MG Yasin, N Begum, MMH Mondal
}

Department of Parasitology, Faculty of Veterinary Science, Bangladesh Agricultural University,

Mymensingh-2202

\begin{abstract}
Onchocercosis is a parasitic disease caused by the different species of nematodes belonging to the genus Ochocerca affecting both humans and animals. Ochocerca armillta, O. gutturosa and O. gibsoni affect mainly cattle, and also buffaloes. Here, we studied epidemio-pathology and vector flies of onchocercosis in cattle in Bangladesh. Out of 310 animals examined, 163 (52.6\%) were infected with different species of Onchocerca. Three species of Onchocerca, namely, Onchocerca armillata (24.8\%), Onchocerca gutturosa (24.7\%) and Onchocerca gibsoni (13.3\%) were identified. We recovered O. armillata only from aorta, O. gutturosa from the ligamentum nuchae and $O$. gibsoni from the subcutaneous nodules. Nodular lesions were detected at the neck (49/20.9\%), abdomen (5/2.1\%), flank (8/3.4\%), brisket (33/14.0\%) and thigh/legs (32/13.6\%) regions. We observed age as a potential diterminant in the occurance of the infection. Prevalence of $O$. armillata and $O$. gutturosa was significantly higher in older animals ( $>4$ years) than yearlings (1-2 years). Sex, breed and rearing system did not significantly influence the prevalence of bovine onchocercosis. Our study revealed that seasons of the year was another important determinant for onchocercosis, and prevalence was the highest in the summer. Grossly, the affected aorta was thickened, dilated and with elevated intima. Histological examination revealed parasitic granuloma present in blood vessels characterized by the infiltration of eosinophils and neumerous sections of the parasites. We identified only Culicoides spp., but no Simulium spp., as a vector from the study area. Vector flies were the most abundant in the early morning and least at noon, and mostly at the umbilical region of cattle. Culicoides spp. were most abundant in the winter. Our results suggest that occurrence of onchocercosis is fairly high in cattle in Bangladesh irrespective to age, sex, breed and management.
\end{abstract}

Key words: Bovine onchocercosis, epidemiology, pathology, vector fly, cattle

Progressive Agriculturists. All rights reserve

*Corresponding Author: zaman.a.bau@gmail.com

\section{Introduction}

Onchocercosis is a parasitic disease caused by different species of Onchocerca (Nematoda: Filaridae) and transmitted by the flies of the genera Simulium and Culicoides affecting humans and animals. Numerous species have been described within the genus Onchocerca, however, three of which are commonly found to infect cattle and buffaloes, such as Onchocerca armillata, Onchocerca gutturosa and Onchocerca gibsoni (Achukwi et al 2004, Soulsby 1982). O. armillata is commonly found in the wall of the aorta, where the other species are found in fibrous connective tissues around the ligamentum nuchae and subcutaneous tissues, mainly in the brisket region. In subcutaneous tissues, they produce honey comb like nodules. Although the nodules are commonly found in brisket, but may also be distributed throughout the body. These parasites may cause damage to the skin of the affected animals. Besides, onchocercal infection predisposes humpsore in cattle which is one of the major limiting factors of the market value of hides. Thus, onchocercosis is associated with great 
economic losses. On the other hand, O. armillata affects the aortic wall resulting fatal outcome (Soulsby 1982, Mtei et al 1990, Nmorsi et al 2002, Beytuket et al 2005). Furthermore, zoonotic significance of bovine onchocercosis has recently been reported (Takaoka et al 2004).

Onchocercosis has been studied in many countries of the world such as North, Central and South Africa, Sudan, Puerto Rico, Turkey, India and Australia. Seddon (1967) recorded that $65 \%$ of the slaughtered cattle in Northern Australia were infected with $O$. gibsoni. Hussain et al. (1975) found $68.5 \%$ and 89.2\% prevalence of $O$. gutturosa and O. armillata, respectively in Sudaneese cattle. Alibasgoglu et al (1969) observed that $80 \%$ cattle in Turkey were infected with $O$. armillata. Bwangamoi (1969) recovered onchocercal parasites from cattle in African countries and considered the parasites as economically important. O. guttorosa and $O$. lienalis have been recovered from British cattle (Trees et al 1987). Onchocercal infection was detected about half a century ago in cattle in Bangladesh (Wolfe and Aslamkhan, 1970, Haq et al. 1977 and Nooruddin et al. 1985). However, epidemiology of onchocercal infection and the pathological changes caused by them in cattle in Bangladesh are yet to be studied which are essential for the planning and execution of a fruitful control program more effectively. The present work was designed to study epidemiology and pathology of bovine onchocercosis in Bangladesh.

\section{Materials and Methods}

Ante-mortem examination: To study the epidemiology and pathology of onchocercosis, we conducted multi-stage, slaughter house-based, antemortem and post-mortem examinations. We randomly selected and examined 310 cattle. Before examination, age, sex, breed and information about rearing were recorded. Then animals were examined by parting of hair against their natural direction, digital palpation and simultaneous close inspection to detect suspected subcutaneous nodules. Size, shape, and consistency of these nodules along with their distribution on the body surface of the affected animals were recorded carefully.
Postmortem examination: Following skinning of the slaughtered cattle, subcutaneous tissues, and muscles were examined and subcutaneous nodules were collected carefully. Collected nodules were thoroughly examined and the gross pathology was recorded. Suspected subcutaneous nodules were preserved in $10 \%$ buffered neutral formalin for histopathological study. Muscle, fasciae, connective tissues, heart, great vessels (especially, aorta) and ligamentum nuchae were collected and examined carefully to detect parasites and the pathological changes.

Collection and identification of parasites: Suspected nodules were excised and kept in a Petridish containing normal saline. Parasites were collected and preserved in glycerin alcohol after gentle washing with normal saline. Onchocerca species were identified according to the keys and descriptions as per Soulsby (1982) and Yamaguti (1961) by preparing temporary slides adding one drop of lactophenol (Cable 1957).

Histopathological study: Formalin fixed tissue were processed, embedded in paraffin and thin $(5 \mu \mathrm{m})$ sections were prepared. The sectioned tissues were stained with haematoxilin and eosin following the procedures described by Luna (1968).

Detection of Vector: Suspected flies were collected and identified according to the keys and descriptions given by Soulsby (1982) and Cable (1957) preparing permanent slides.

Statistical analysis: Data were presented as mean \pm SEM. For multiple group comparisons one-way ANOVA followed by post-hoc Bonferroni analysis was used. For direct comparisons, unpaired 2-tailed student's $t$ test was employed. A value of $P<0.05$ was considered as significant. Odd ratio was calculated according to the formula given by Schlesslman (1982).

\section{Results and Discussion}

Overall prevalence of onchocercosis in cattle is fairly high in Bangladesh: Out of 310 animals examined, 163 (52.58\%) were infected with Onchocerca spp. (Table 1). We identified three species of Onchocerca, namely, O. armillata, O. 


\section{Onchocercosis in cattle in Bangladesh}

gutturosa and O. gibsoni from cattle (Figure 1). Of the species identified, prevalence of $O$. gutturosa was the highest $(86 / 27.7 \%)$ followed by that of $O$. armillata (77/24.8\%) and O. gibsoni (41/13.3\%). The mean parasitic burden of $O$. armillata $(2.02 \pm 0.18)$ was higher than $O$. gutturosa $(1.91 \pm 0.19)$ showing overall parasitic burden per nodule $1.97 \pm 0.13$ (Table 1). Our findings were lower than those of Takaoka et al (2004), Anosike et al (2001), Hussain et al (1975) and Seddon et al (1967) who recorded 46-92\% onchocercosis in cattle. In contrast, the present findings were higher than the findings of Pazhanivel et al (2006) who recorded $4.62 \%$ prevalence of bovine onchocercosis.

Table 1. Overall prevalence of Onchocerca spp. infection in cattle

\begin{tabular}{|l|c|c|c|}
\hline \multicolumn{1}{|c|}{ Parasite } & Animal & \multicolumn{2}{|c|}{ Parasitic burden } \\
\cline { 3 - 4 } & infected (\%) & Range & Mean+SE \\
\hline O. gutturosa & $86(24.7)^{\mathrm{a}}$ & $1-9$ & $1.91 \pm 0.19$ \\
\hline O. armillata & $77(24.8)^{\mathrm{a}}$ & $1-8$ & $2.02 \pm 0.18$ \\
\hline O. gibsoni & $41(13.3 \%)^{\mathrm{b}}$ & $1-6$ & $1.8 \pm 0.9$ \\
\hline Total & $163(52.6)$ & $0-9$ & $1.97 \pm 0.13$ \\
\hline
\end{tabular}

$n=310$, values with the same superscript in the same column are statistically insignificant but values with different superscripts are statistically significant $(\mathrm{p}<0.05)$.

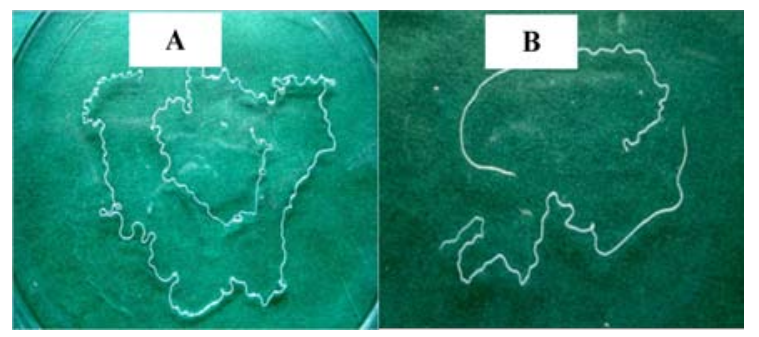

Figure 1. Parasites recovered from the subcutaneous nodules. Parasites were collected and preserved in glycerin alcohol after gentle washing with normal saline, and photographs were taken. (A) O. guttorosa (B) O. armilata.

The discrepancies among the present and previous studies might be due to variation in the geographical locations, climatic conditions of the experimental area, method of study and availability of vectors. Also, distribution of these three parasites were strictly organ specific, and we recovered $O$. gutturosa from ligamentum nuchae, O. armillata from aorta and O. gibsoni from subcutaneous nodules.

Age significantly influences the prevalence of onchocercosis in cattle: We observed that age of the host had an effect on the prevalence of onchocercosis in cattle. In case of $O$. gutturosa, prevalence was significantly $(\mathrm{p}<0.01)$ higher in adult cattle $(57.5 \%)$ than yearlings (40\%). Calculated odds ratio implied that older cattle were 1.5 and 1.12 times more susceptible to $O$. gutturosa than yearlings and young, respectively (Table 2), which conformed to those of Anosike et al (2001). Anosike et al (2001) reported that prevalence of onchocercosis was significantly $(p<0.05)$ higher in aged cattle $(59.8 \%)$ than those in younger cattle (36.7\%). Similarly, in case of $O$. amillata, prevalence was significantly $(\mathrm{p}<0.01)$ higher in adult cattle (55.2\%) than yearlings (21.4\%). Calculated odds ratio implied that older cattle were 4.51 and 1.08 times more susceptible to O. amillata than yearlings and young, respectively (Table 3). These findings conformed to the findings of Pazhanivel et al (2006), and they showed that cattle aged more than 2 years old were mostly affected (7.09\%) with O. armillata. It is difficult to explain the exact mechanism how age of the animals influenced the prevalence of the parasites but it may be assumed that the exhausted immune system of the older animals had an effect in this regard.

Effect of sex of the animal on the occurrence of bovine onchocercosis is inconclusive: Effects of sex of the host on the prevalence of bovine onchocercosis caused by $O$. gutturosa were statistically insignificant. The present study revealed that prevalence of $O$. gutturosa infection was little bit higher in females (55.6\%) than that in males (52.6\%), and females were 1.12 times more susceptible to the infection (Table 2). This finding was supported by the findings of Anosike et al (2001) and Hussain et al (2000) who reported slightly higher prevalence of $O$. gutturosa infection in females. In contrast, prevalence of $O$. armillata was significantly $(\mathrm{p}<0.05)$ higher in females $(56.1 \%)$ than that in males (44.9\%), and females were 1.56 times more susceptible to $O$. armillata than male (Table 3). This finding was in agreement with the earlier findings of Pazhanivel et al (2006) who 
reported significantly higher prevalence of $O$. armillata in females (6.57\%) than males (0.69\%). Also, Ebong et al (2007) reported the higher prevalence of onchocercosis in females (57.5\%) than in males $(42.5 \%)$. In the contrary, Okwa (2004) reported relatively higher prevalence of onchocercosis in males (53.72\%) than females (31.6\%). However, Vivas et al (2000) reported almost similar prevalence of onchocercosis in males (42.5\%) and females (41.5\%). Therefore, it was difficult to consider sex of the animal as a leading determinant of the infection.

Table 2. Effect of age, sex and seasons on the prevalence of $O$. gutturosa infection in cattle

\begin{tabular}{|c|c|c|c|c|}
\hline \multirow{2}{*}{\multicolumn{2}{|c|}{ Parameters }} & \multirow{2}{*}{$\begin{array}{c}\text { Animal affected } \\
\text { (\%) }\end{array}$} & \multicolumn{2}{|c|}{ Parasitic burden } \\
\hline & & & Mean \pm SE & Odds Ratio \\
\hline \multirow{3}{*}{ Age } & $\begin{array}{c}\text { Yearling } \\
(1-2 \text { yrs, } n=15)\end{array}$ & $6(40)^{\mathrm{a}}$ & $0.87 \pm 0.35$ & Young vs yearlings $=1.8$ \\
\hline & $\begin{array}{c}\text { Young } \\
(>2-4 \text { yrs, } n=97)\end{array}$ & $53(54.6)^{b}$ & $2.14 \pm 0.24$ & Adult vs young=1.12 \\
\hline & $\begin{array}{c}\text { Adult } \\
(>4 \mathrm{yrs}, \mathrm{n}=47)\end{array}$ & $27(57.5)^{b}$ & $2.13 \pm 0.32$ & Adult vs yearlings=1.5 \\
\hline \multirow{2}{*}{ Sex } & Male $(n=78)$ & $41(52.6)^{\mathrm{a}}$ & $2.01 \pm 0.27$ & \multirow[t]{2}{*}{ Female vs male $=1.12$} \\
\hline & Female $(\mathrm{n}=81)$ & $45(55.6)^{\mathrm{a}}$ & $2.02 \pm 0.25$ & \\
\hline \multirow{3}{*}{ Seasons } & Rainy (n=60) & $34(56.7)^{\mathrm{a}}$ & $1.95 \pm 0.27$ & Rainy vs winter=1.46 \\
\hline & Winter $(\mathrm{n}=72)$ & $34(47.2)^{b}$ & $1.72 \pm 0.26$ & Summer vs winter $=2.26$ \\
\hline & Summer $(\mathrm{n}=27)$ & $18(66.7)^{\mathrm{c}}$ & $2.96 \pm 0.52$ & Summer vs rainy=1.52 \\
\hline
\end{tabular}

$n=310$, values with the same superscript in the same column are statistically insignificant but values with different superscripts are statistically significant $(\mathrm{p}<0.05)$.

Table 3. Effect of age, sex and seasons on the prevalence of $O$. armillata infection in cattle

\begin{tabular}{|c|c|c|c|c|}
\hline \multicolumn{2}{|c|}{ Parameters } & \multirow{3}{*}{$\begin{array}{c}\begin{array}{c}\text { Animals affected } \\
(\%)\end{array} \\
3(21.4)^{\mathrm{a}}\end{array}$} & \multicolumn{2}{|c|}{ Parasitic burden } \\
\hline & & & Mean \pm SE & Odds Ratio \\
\hline \multirow{3}{*}{ Age } & $\begin{array}{c}\text { Yearlings } \\
(1-2 \text { yrs, } n=14)\end{array}$ & & $0.71 \pm 0.44$ & Young vs yearlings $=4.16$ \\
\hline & $\begin{array}{c}\text { Young } \\
(>2-4 \text { yrs, } n=79)\end{array}$ & $42(53.2)^{b}$ & $2.14 \pm 0.28$ & Adult vs young=1.08 \\
\hline & $\begin{array}{c}\text { Adult } \\
(>4 \mathrm{yrs}, \mathrm{n}=58)\end{array}$ & $32(55.2)^{b}$ & $1.90 \pm 0.27$ & Adult vs yearlings $=4.51$ \\
\hline \multirow{2}{*}{ Sex } & Male (n=69) & $31(44.9)^{\mathrm{a}}$ & $1.58 \pm 0.24$ & \multirow{2}{*}{ Female vs male $=1.56$} \\
\hline & Female $(\mathrm{n}=82)$ & $46(56.1)^{b}$ & $2.20 \pm 0.27$ & \\
\hline \multirow{3}{*}{ Seasons } & Rainy $(\mathrm{n}=68)$ & $34(50.0)^{\mathrm{a}}$ & $1.81 \pm 0.27$ & Rainy vs winter $=1.12$ \\
\hline & Winter $(n=66)$ & $31(46.9)^{\mathrm{a}}$ & $1.76 \pm 0.28$ & Summer vs winter $=2.7$ \\
\hline & Summer $(\mathrm{n}=17)$ & $12(70.6)^{b}$ & $2.94 \pm 0.58$ & Summer vs rainy $=2.5$ \\
\hline
\end{tabular}

$n=310$, values with the same superscript in the same column are statistically insignificant but values with different superscripts are statistically significant $(\mathrm{p}<0.05)$.

Breed and management systems did not significantly affect bovine onchocercosis: Our study revealed that the prevalence of onchocercosis in cattle was little bit higher in cross bred cattle (58.0\%) than in indigenous (50.4\%) cattle (Figure 2). Prevalence of onchocercosis was almost similar in cattle reared in intensive system (59.1\%) and in those reared in semi-intensive system (52.9\%) (Figure 2), 
indicating that breed and management system did not play vital roles in the prevalence of the disease.

\section{Seasons of the year significantly influenced} prevalence of onchocercosis: During this study, it was observed that seasons of the year had a profound effect on the prevalence of onchocercosis in cattle. In case of $O$. gutturosa, the prevalence was significantly $(\mathrm{p}<0.01)$ higher in summer season (66.6\%) followed by rainy (56.7\%) and the lowest in winter (47.2\%) seasons. Calculated odd ratio implied that in the summer season cattle were 2.26 and 1.52 times more susceptible to $O$. gutturosa infection than in winter and rainy seasons, respectively.

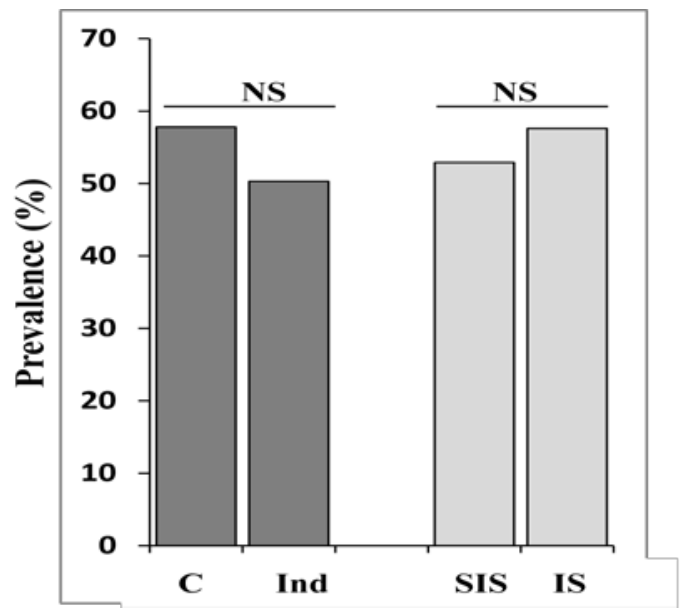

Figure 2. Effects of breed and management system on the prevalence of onchocercosis. We randomly selected and examined 310 cattle, and breed and information about rearing were recorded. Subcutaneous nodules were detected by clinical examinations. Parasites were collected and identified. Breed and management system did not play a vital role in the prevalence of the disease. C, cross-bred; Ind, indigenous; SIS, semi-intensive system; IS, intensive system, NS, non significant.

On the other hand, in rainy season, cattle were 1.46 times more vulnerable to $O$. gutturosa than in the winter (Table 2). Also, prevalence of $O$. amillata was significantly $(\mathrm{p}<0.01)$ higher in summer season (70.6\%) followed by rainy (50\%) and winter (46.9\%) seasons. And, in the summer season cattle were 2.7 and 2.5 times more susceptible to $O$. amillata than in winter and rainy seasons, respectively. In rainy season, cattle were 1.12 times more vulnerable to $O$. armillata than winter season (Table 3). Our findings were in contrast to the findings of Pazhanivel et al (2006) who observed the highest prevalence of $O$. armillata during monsoon (6.73\%). The variation among the present and previous studies might be due to the spatial variation and climatic changes. Onchocercosis is a fly-borne disease so temporal distributions of the infection observed in this study was more logical in our country contest.

Distribution of subcutaneous onchocercosis in cattle: Initially, we detected subcutaneous nodules through atne-mortem examinations then we confirmed subcutaneous onchocercosis by postmortem examination and parasite collection from the suspected lesions, and subsequent identification of the parasites. Through detail ante-mortem and postmortem examinations, we found nodular lesions of subcutaneous onchocercosis in neck 49 (20.85\%), abdomen 5 (2.12\%), flank 8 (3.40\%), brisket 33 (14.04\%) and thigh/legs 32 (13.61\%) regions (Figure 3). It is difficult to explain exactly why nodular lesions were higher in the neck region, however, it may be due to the organ specificity.

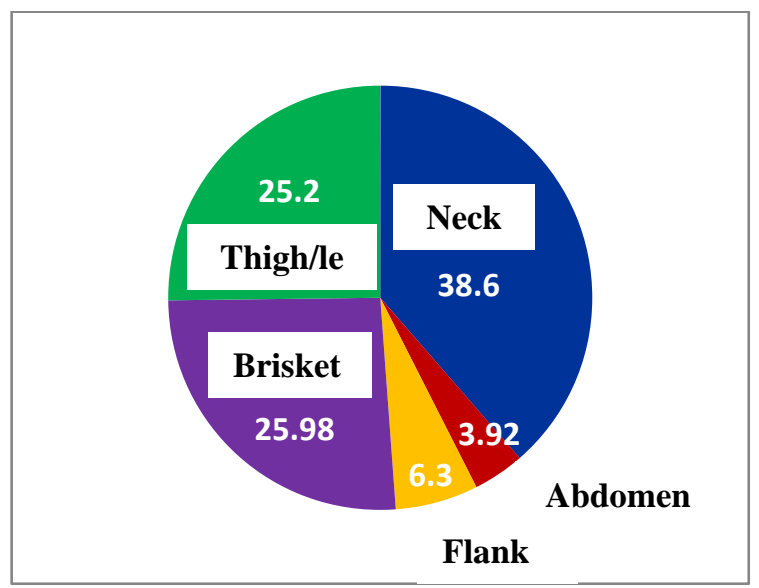

Figure 3. Distribution of nodules of subcutaneous onchocercosis on the body surface. Subcutaneous nodules from 310 randomly selected cattle were detected by clinical examinations. Parasites were collected and identified.

Gross and histopathological changes: Grossly, the affected aorta showed thickened, dilated and elevated tortuous tracts of atheromatous plaques on the intimal surface. The worms within a nodule were usually observed. These findings were similar with 


\section{Onchocercosis in cattle in Bangladesh}

the findings of Pazhanivel et al. (2006) who observed that the affected aorta became thickened, dilated, elevated and tortuous with the tracts of atheromatous plaques. Microscopically, neumerous sections of the parasite (O. armillata) were found in the wall of aorta. Parasitic granulomas were infiltrated with eosinophils. Parasites were embedded or encysted in the inner most layer of blood vessel. Multifocal area of accumulation of macrophages and fibroblasts were found in the wall of aorta and ligamentum nuchae. This finding was supported by the findings of Solismaa et al (2008) and Kmnenou et al (2002) who reported mild to intense infiltration with eosinophilic granulocytes and multifocal nodular lymphoplasmacytic aggregations in aorta. There were granulomatous lesions with central necrotic tissue and cell detritus surrounded by eosinophilic granulocytes, lymphocytes, plasma cells and histiocytes and some multinucleated giant cells (Figure 4 A-D).
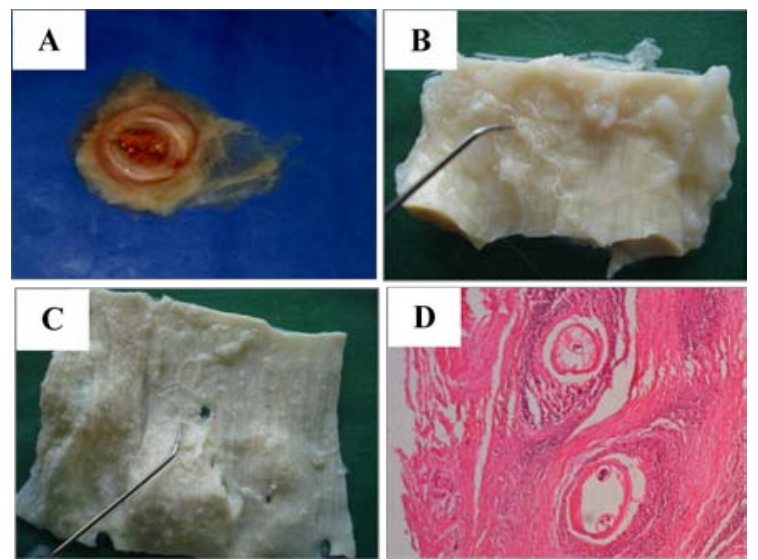

Figure 4. Gross and histopahtological features of onchocercosis. (A-C) Gross features of onchocercosis. The slaughtered animals were skinned off and suspected tissues were collected. (A) Subnucutaneous nodule, (B) ligamentum nuchae and (C) aortic lesion. (D) Histology of vascular onchpocercosis. Heart and great vessels (especially, aorta) were collected and examined carefully to detect parasites and the pathological changes. Formalin fixed tissue were processed, and thin sections were prepared and stained with haematoxilin and eosin.
Culicoides spp. were detected of from the study areas: Plethora of literatures support that both Culicodes spp and Simulium spp act as a vector for bovine onchocercosis (Soulsby 1982 and Urquhart et al 1996). However, we could detect only Culicoides spp., but no Simulium spp., from the study areas (Figure 5). We also studied the temporal distribution of vector flies. Multiple visit to the same areas confirmed that Culicoides spp. were more abundant in the early morning followed by in the evening and least at noon. Flies mostly attacked to the neck and umbilical regions of the animals. Seasons also had significant effect on the abundence of vector flies. Culicoides spp. was most abundant in the winter followed by rainy season and the least in the summer.

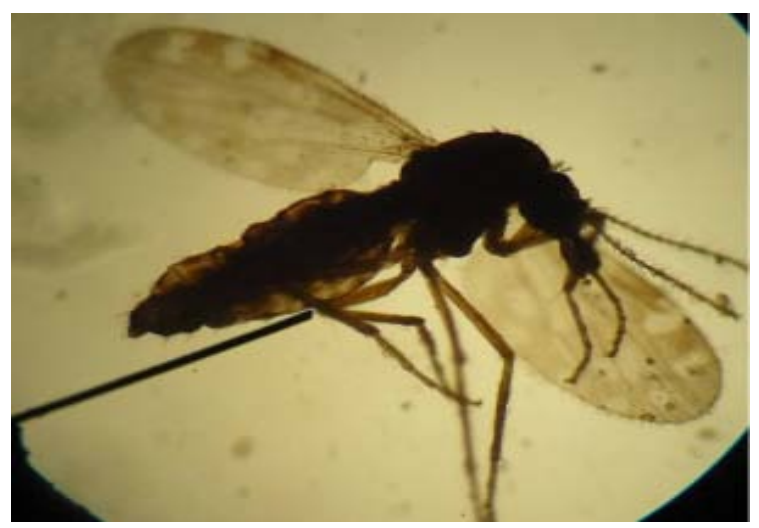

Figure 5. Vector fly of onchocercosis. Vector flies were collected and identified. Culicoides spp. were detected from the study areas.

Our study revealed that the prevalence of onchosercosis was fairly common in cattle in Bangladesh. Age of the host and season of the year are the leading determinants which greatly influence the occurrence of the disease. Vector flies are available in our country and most abundant in winter season. Baseline data generated from the study will be helpful for the formulation of a fruitful control strategy.

\section{Acknowledgements}

This work was supported by a grant (to $\mathrm{MMH}$ Mondal) from Bangladesh Agricultural University Research System (BAURES, project no.: 2008/11/AUGC), Bangladesh Agricultural University (BAU), Mymensingh-2202, Bangladesh. 
We are grateful to the Department of Pathology, Faculty of Veterinary Science, BAU for their generous help in preparing histological sections.

\section{References}

Achukwi, M.D., Harnett, W., Bradley, J. and Renz, A. 2004. Onchocerca spp. acquisition in zebu Gudali cattle exposed to natural transmission, parasite population dynamics and IgG antibody subclass responses to recombinant antigens Amsterdam, Netherlands. Veterinary Parasitology, 122: 35-49.

Alibasgoglu, M., Goksu, K., Ertiirk, E. and Guler, S. 1969. Orchocerca armillata infection in cattle in Turkey. Veterinary Journal of Ankara University. 16:50-60.

Anosike, J.C., Okoli, I.C., Okoli, C. G. and Ekeh, I.K. 2001. The prevalence and anatomical distribution of bovine onchocercosis in Bassa Local Government Area of Plateau State, Nigeria. Bulletin of Animal Health and Production in Africa, 49: 262-267.

Beytuk, E., Akca, A. and Bain, O. 2005. Teat onchocercosis in cows with reference to prevalence, species involved and pathology in Amsterdam, Netherlands. Elsevier Research in Veterinary Science. 78: 45-51.

Bwangamoi, O. 1969. Dermatitis in cattle caused by Orchocrca hengi and the effect of the adult filaria on the furnished leather. Bulletin of Epizootic Diseases in Africa. 17: 433-443.

Cable, R.M. 1967. An Illustrated Laboratory Manual of Parasitology, $4^{\text {th }}$ edition, Burgess Publishing Co. Minneapolis 15, Minnesota, pp.127-132.

Ebong, C.E., Alemnji, G.A., Ashuntantang, G. and Asonganyi, T. 2007. Proteinuria and onchocercosis in an endemic area in Cameroon under community-based treatment with ivermectin in London, UK. Royal Society of Medicine. 37: 156-158.

Haq, S., Rahman, M. H. and Dewan, M. L. 1977. A study on the incidence of onchocercal parasites in cattle in Bangladesh. Bangladesh veterinary Journal. 11:63-64.

Hussain, M.F., Abdul, N. Gassouma, M.S. and Nelson, G.S. 1975. Onchocerca gutturosa infection in suddanese cattle. British Veterinary Journal. 131:76-84.

Komnenou, D., Sakthivelan, S.M. and Manohar, B. M. 2002. Histologic and parasitological examination of tissues and parasites in cattle. Journal of Veterinary Parasitology. 31:67-82.

Luna, L.G. 1968. Manual of Histologic Staining Methods of the Armed Forces Institute of Pathology, $3^{\text {rd }}$ edition. McGraw Hill Book Co. New York.

Mtei, B.J. and Sanga, H.J.N. 1990. Aortic onchocerciosis and Elaeophorosis in Traditional TSZ-Cattle in Tabora (Tanzania): Prevalence and Pathology. Veterinary Parasitology, 36:165-170.

Nmorsi, O.P.G., Oladokun,I.A.A., Egwunyenga,O.A. and Oseha, E. 2002. Eye lesions and onchocercosis in a rural farm settlement in Delta State, Bangkok, Thailand. Southeast Asian Journal of Tropical Medicine and Public Health, 33: 28-32.

Nooruddin, M. and Baki, M. A. 1985. A survey of subcutaneous nodules in cattle. Bangladesh Veterinary Journal, 10: 24-29.

Okwa, O. O. 2004. Onchocercosis in two communities in Oyo State, Lagos, Nigeria. Nigerian Journal of Health and Biomedical Sciences. 3: 89-92.

Pazhanivel, N., Balachandran, C., Sakthivelan, S. M. and Manohar, B. M. 2006. Prevalence of bovine onchocercosis in Chennai, India. Indian-Veterinary Journal, 83: 666-667.

Schlessman. J.J. 1982. Case control studies. $1^{\text {st }}$ edition, Oxford university press, New York, pp. 174-177.

Seddon, H.R. 1967. Diseases of Domestic Animals in Australia. Part-1, Commonwealth Government Printer, Canberra.

Solismaa, M., Laaksonen, S., Nylund, M., Pitkanen, E., Airakorpi, R. and Oksanen, A. 2008. Filarioid nematodes in cattle, sheep and horses in Finland. Acta Veterinaria Scandinavica, 50:612-624

Soulsby, E. J. L. 1982. Helminths, Arthropods and Protozoa of Domesticated Animals, $7^{\text {th }}$ edition, Bailliere Tindall and Cassel Ltd. London. pp. 35-740. 
Takaoka, H., Bain, O., Uni, S., Korenaga, M., Kozek, W. J., Shirasaka, C., Aoki, C., Otsuka, Y., Fukuda, M., Eshita, Y. and Daa, T. 2004. Zoonotic onchocerciasis caused by a parasite from wild boar in Oita, Japan and a comprehensive analysis of morphological characteristics of the worms for its diagnosis. Medical Entomology and Zoology. 11: 285-292

Trees, A. J., McCall, P.J. and Crozier, S. J. 1987. Onchocercosis (Onchocerca gutturosa and $O$. lienalis) in British cattle in North Wales. Journal of Helminthology. 61:103-113.

Urquhart, G. M., Armour, J., Duncan, J. L., Dunn, A. M. and Jennings, F. W. 1996. Veterinary
Parasitology. $2^{\text {nd }}$ edition, Blackwell Science Ltd. Oxford, UK. pp 146-149.

Vivas, S., Basanez, M. G., Botto, C., Rojas, S., Garcia, M., Pacheco, M. and Curtis, C.F. 2000. Amazonian onchocercosis and parasitological profiles by host-age, sex, and endemicity in southern Venezuela. Journal of Parasitology. 121: 513-525.

Wolfe, M. S. and Aslamkhan, M. 1970. Bovine filariasis in Dinajpur district, East Pakistan. The Journal of Parasitology. 56: 404-405.

Yamaguti, S. 1961. Systema Helminthum, The nematodes of vertebrates. 3:1261. 